\title{
MÉXICO Y EL TLCAN, VEINTE AÑOS DESPUÉS ${ }^{1}$
}

Alain RouQuié

1994, “AÑo TERRIble” PARA México, es también un momento crucial en la historia contemporánea del país: el primero de enero el Tratado de Libre Comercio de América del Norte (TLCAN) entraba en vigor. Desde entonces, a lo largo de estos últimos veinte años México se ha transformado profundamente en todos los ámbitos. Nos proponemos examinar aquí los cambios ocurridos durante estas dos décadas a la luz de eso que ha representado y que representa el tratado norteamericano. Dicho de otra manera, cómo y hasta qué punto ha afectado este tratado comercial la economía, la sociedad, la política y las políticas de México. No se trata de establecer un balance, lo que sería prematuro e imprudente, sino apenas de establecer un enfoque distanciado y comparado de las repercusiones en México de la puesta en práctica del libre comercio norteamericano.

Se revisa primero el sentido y el impacto global de la apuesta norteamericana de 1994. Después examinamos el modelo económico de México después del tLCAN y sus consecuencias sociales antes de evaluar el rol eventual jugado por el "giro hacia el Norte" en la transición democrática, en la actividad exterior y en el estatuto internacional del país.

${ }^{1}$ Este artículo es una versión revisada y adaptada de una conferencia dictada en El Colegio de México el 14 de noviembre de 2014. Puede encontrarse una exposición más por extenso en mi libro: Le Mexique, un État nord-Américain, París, Fayard, 2013. 
I) LA APUESTA NORTEAMERICANA: ¿UNA TRANSICIÓN HISTÓRICA?

A primera vista, y para un observador del exterior, el Tratado de Libre Comercio de América del Norte es para México mucho más que un acuerdo que liberaliza gradualmente el comercio exterior con sus dos vecinos septentrionales; la historia de México no puede entenderse en toda su complejidad sino a partir de su excepcional situación geopolítica. La contigüidad de este "país del sur situado en América del Norte" con la República imperial, que ha llegado a ser la primera potencia mundial en el siglo xx, y la enorme asimetría entre los dos Estados, marcaron el destino de México. Ningún país del mundo ha experimentado más la influencia directa y permanente de Estados Unidos. La pérdida de la mitad del territorio, las reiteradas intervenciones militares al sur del Río Bravo por parte del expansionismo norteamericano hasta el siglo xx, constituyen referencias esenciales de la identidad mexicana. Es por eso que al término de la Revolución de 1910, durante la cual la injerencia estadounidense se manifestó de forma continua desde el asesinato de Madero a las amenazas, del presidente Coolidge, de intervención armada contra Calles, ${ }^{2}$ el país se hubo de cerrar en una actitud eminentemente defensiva. Se hace así de una legislación acorazada con prohibiciones y restricciones que se dirigen ante todo contra "el enemigo extranjero", al que hace alusión el himno nacional; la Constitución de 1917 es manifiestamente una ley fundamental nacionalista; la economía, hasta la década de 1980 , queda protegida y poco abierta; y en el dominio internacional, la diplomacia mexicana está sujeta a una defensa sin concesiones de la soberanía nacional. Esto se traduce en un arsenal de principios jurídicos universales y no negociables que forman una "política de Estado" al margen de la coyuntura.

El régimen autoritario híbrido del Partido de la Revolución, bajo sus diferentes denominaciones, es una "dictadura invisible"3

2 Véase Jean Meyer, Enrique Krauze, Cayetano Reyes, Historia de la Revolución Mexicana (1921-1928). Estado y sociedad con Calles, México, El Colegio de México, 1977, pp. 120-122.

3 "Invisible" me parece una calificación más exacta que "perfecta", según la fórmula de Mario Vargas Llosa, que causó escándalo en México en 1990. 
destinada a eliminar los conflictos políticos en nombre de la defensa de la unidad nacional y de la soberanía. Queda sobrentendido en esta perspectiva autocrítica que el pluralismo competitivo volvería al país demasiado vulnerable ante las amenazas que la geografía le impone. La incertidumbre electoral iba a debilitar demasiado la capacidad de resistencia soberana de la nación.

Así las cosas, se puede entonces considerar que la reaproximación con Estados Unidos y la apertura norteamericana han sido una verdadera ruptura con el orden revolucionario y la narrativa nacional. México pareció repentinamente devoto hacia lo que antes repudiaba. La amenaza geopolítica se había vuelto de súbito "un privilegio económico", que lo beneficiaba con un acceso garantizado al mercado más grande del mundo. La apuesta norteamericana representaba un reconocimiento tardío, aunque entusiasta, por parte del régimen revolucionario, de las realidades de la economía. ¿No se había convertido México en el segundo socio comercial de Estados Unidos (antes de que lo destronara China) y Estados Unidos a su vez en el principal inversionista directo de su vecino del sur?

La política de promoción de las exportaciones tomada por México a partir de 1982 ha acarreado una mutación de la economía nacional. Ante el ensanchamiento del modelo sostenible de industrialización por sustitución de importaciones, los dirigentes adquirieron conciencia de la necesidad de integrarse al mercado mundial, única solución para remontar las limitaciones del mercado interior. En la década de 1990, México se convirtió en el primer exportador de América Latina, muy por delante de Brasil. Sus exportaciones crecieron más rápido que su producto interno bruto; pasaron de $6.5 \%$ del PIB en 1970 a $27 \%$ en 1990. En este contexto, el acceso asegurado y libre al mercado norteamericano era la única opción de una globalización de proximidad.

De hecho, el tratado de libre comercio norteamericano no fue un proyecto aislado ni un cambio de trayectoria inesperado; era por el contrario el resultado de un vasto programa de reformas estructurales que daba vuelta a la página del modelo "nacionalpopular" del régimen de la Revolución. El tratado viene en efecto a consolidar y perpetuar el nuevo curso liberal de la economía 
mexicana. Los gobiernos sucesivos desde 1982 han proseguido con determinación políticas que abren la economía; hubo algunos momentos importantes, como la entrada al GATT, rehusada hasta entonces, pues sus normas comerciales y tarifarias condenan el proteccionismo. A partir de 1988 el gobierno dio prioridad absoluta a una "reconversión productiva" que desregulaba y liberalizaba todos los sectores económicos. Con la excepción de la energía y de las vías ferroviarias, la mayoría de las empresas públicas se privatizaron, lo que dio lugar a la cesión más importante de activos de un Estado en América Latina. Por último, una decisión asaz simbólica en materia social, la supresión del ejido, coronó a esta política sorprendente. Al modificar la constitución para autorizar a los campesinos a vender su parcela, esta "reforma de la reforma agraria", que ponía fin a la redistribución de tierras, marcaba el fin de la Revolución mexicana y su carácter "agrarista” y comunitario.

Se puede entonces estimar que en principio el TLCAN tenía por objetivo la consolidación de un nuevo modelo económico. Si bien no suscitó ni aceleró las reformas liberales en curso, determinó en cierto modo la transformación de la economía nacional emprendida en los años ochenta. En un discurso pronunciado en marzo de 1991, Jaime Serra Puche, secretario de Comercio y Fomento Industrial y principal negociador del tratado, preocupado por las dificultades que encontró en Estados Unidos, declaró que sin el TLCAN "la política económica de México estaría en peligro". ${ }^{4}$ Paul Krugman, economista contestatario y futuro Premio Nobel, respondía en un artículo de Foreign Affairs a los adversarios estadounidenses del tratado que temían la deslocalización de empresas al sur del Río Bravo, que el tLcan tenía ante todo un carácter político. Se trata, escribía, de ayudar a un presidente propicio al comercio y favorable a Estados Unidos, y del "mejor gobierno en la historia de México". Gracias a este tratado, Estados Unidos tendría a un vecino amigable, estable y com-

${ }^{4}$ Jaime Serra Puche, El Tratado de Libre Comercio [discurso], México, Secofi, 1 de marzo de 1991. 
prensivo. ${ }^{5}$ Por ello, era indispensable asegurar a los inversionistas que el mercado norteamericano quedaría abierto a las exportaciones mexicanas y que las reformas pro mercado no se iban a abandonar.

Si bien es cierto que el TLCAN no causó mucho entusiasmo en la opinión pública norteamericana -por no decir la hostilidad de los sindicatos de obreros-, en México la oposición fue relativamente moderada y discreta. Es verdad que el éxito de este gran proyecto fue la prioridad y en cierto modo el eje central del sexenio de Carlos Salinas. Se movilizó un amplio dispositivo de comunicación para sensibilizar y convencer a la opinión pública y asegurar el éxito de las negociaciones. Los críticos, del lado mexicano, surgieron sólo de las asociaciones campesinas independientes y de grupos de intelectuales. De parte de los partidos políticos, el Partido Acción Nacional se complació en ver realizarse su programa económico. Sólo una minoría católica antiamericana expresó su malestar. ${ }^{6}$ En el Partido de la Revolución Democrática se aceptaba aparentemente la apertura hacia el Norte, pero con la demanda de que se extendiera a la movilidad de los trabajadores y de que los mexicanos afectados por la liberalización del comercio regional recibiesen compensaciones adaptadas. ${ }^{7} \mathrm{El}$ carácter limitado de las reacciones puede explicarse por la exclusión de las negociaciones del tratado del monopolio de Estado, el sector energético. Sin embargo se puede señalar que los opositores no tenían proyecto alternativo alguno para hacer valer. Parecían incluso haber olvidado que en el origen era el presidente Ronald Reagan quien había propuesto a México, sin éxito, establecer una zona de libre comercio. Para los partidarios del acuerdo y del modelo liberal, el punto de referencia era la argumentación dogmática de Margaret Thatcher: no había alternativa. Es cierto que el nacionalismo que se identificaba hacía mucho con la Revolución y su régimen había retrocedido considerablemente.

${ }^{5}$ Paul Krugman, “The Uncomfortable Truth about NAFTA: It's Foreign Policy, Stupid”, Foreign Affairs, 5, 1993, pp.13-19.

${ }^{6}$ Véase por ejemplo José Ángel Conchello, El TLC, un callejón sin salida, México, Grijalbo,1992.

${ }^{7}$ Cuauhtémoc Cárdenas, “TLC, una propuesta alternativa”, Nexos, junio de 1991. 
Una investigación de la Universidad de Michigan organizada simultáneamente en los tres Estados de América del Norte daba para México resultados significativos al respecto: $75 \%$ de los mexicanos estaban de acuerdo con el libre comercio (regional) "sin condiciones ni restricciones", contra 37\% de los estadounidenses. Más aún, 59\% de los mexicanos aceptarían que México y Estados Unidos se "fusionaran en un solo Estado" si eso "pudiera mejorar la calidad de su vida". ${ }^{8}$ En consecuencia, no sorprende que en los medios populares se hubiera podido creer que el TLC facilitaría la migración a Estados Unidos.

Sobre este punto, sin embargo, la publicidad oficial era clara. El eslogan "exportar productos, no trabajadores" era razonable y convincente; y era plenamente falaz, como lo probaron los flujos migratorios posteriores a 1994. La hábil comunicación pública tenía con todo otras temáticas a su disposición adaptadas a diferentes estratos sociales. Una de las más sutiles y administrada discretamente fue aquello que se podría llamar "el espejismo del primer mundo”. México, que desde entonces participaría en la economía de dos grandes Estados industriales, ¿no pasaría a formar parte del mundo desarrollado? ${ }^{9}$ La prueba de este salto cualitativo fue sin duda la entrada de México, en 1994, al club exclusivo de los países ricos que suponía ser la Organización para la Cooperación y el Desarrollo Económicos (OCDE). Este ascenso internacional inesperado y paradójico resumía de cierta forma el proyecto modernizador que perseguía el gobierno mexicano: crear una economía del primer mundo merced a un régimen del tercer mundo. Es con la conjunción de un sistema autoritario obsoleto y de una comunicación eficiente como el Estado revolucionario cambió la página de la Revolución.

8 "Integración económica y nacionalismo. Canadá, Estados Unidos y México”, Este País, abril de 1991.

${ }^{9}$ En Argentina, Carlos Menem, presidente de 1989 a 1999, cuyo programa ultraliberal económico tenía la misma inspiración que aquel de Carlos Salinas, introdujo en 1991 la "convertibilidad" efectiva peso/dólar, que produjo efectos sociales e ilusiones similares. 


\section{II) ECONOMía y SOCIEDAd dE UN "PAÍs TLCAN"}

En febrero de 2014 los dirigentes de los tres Estados norteamericanos se reunieron en Toluca. Esta Séptima Cumbre marcaba los veinte años de la entrada en vigor del tratado. No les faltó celebrar el éxito económico del libre comercio regional al recordar que el comercio entre los países miembros se había cuadriplicado y que las inversiones cruzadas se habían multiplicado por cinco desde 1994. ${ }^{10}$ En cuanto a si el acuerdo comercial favoreció el crecimiento y creó más empleos, "es técnicamente imposible de determinar a causa de la multiplicidad de factores que intervienen", como escribió el expresidente de México Ernesto Zedillo. ${ }^{11}$ Con todo, la mayor parte de los analistas coincidió en reconocer que la integración comercial no aportó a México la "convergencia" esperada con los niveles de vida y bienestar de los países desarrollados en general, ni de sus dos vecinos prósperos en particular. México no consiguió realizar en dos decenios el gran salto hacia adelante que habían sabido hacer, en Asia, Corea del Sur y Taiwán.

Es arriesgado tratar de distinguir en la trayectoria económica de los últimos veinte años las consecuencias directas del tratado, pero no es inútil separar los efectos de los mecanismos del mercado de las decisiones propiamente políticas. Bajo este ángulo, por lo demás, las consecuencias del acercamiento entre México y Estados Unidos son particularmente significativas. Así, más allá de la crisis financiera de 1994-1995, el presidente Bill Clinton se apuró a reunir los medios necesarios para el rescate financiero del vecino meridional de Estados Unidos. Esta intervención no obedecía solamente al temor del "efecto tequila" y de un contagio sistémico, sino que debía mucho a una interdependencia oficializada por el tratado de libre comercio. La división regional del trabajo industrial, las inversiones y los compromisos financieros de los bancos estadounidenses no permitían ya el descuido

${ }^{10}$ Véase Excélsior, 20 de febrero de 2014; también: "Three Countries or One Continent", The Economist, 4 de octubre de 2014.

${ }^{11}$ Ernesto Zedillo Ponce de León, "NAFTA, 20: Where We Go From Here", Americas Quarterly, 20 de febrero de 2014, en http://www.americasquarterly.org. content/nafta-20-where-we-go- here 
benigno (benign neglect) de antaño. Estados Unidos ya no podía tolerar una depresión caótica en su vecino. Es por esto que en 1995 la crisis tuvo corta duración y la recuperación de la economía mexicana no tardó mucho. Mientras que después del desplome financiero de 1982 México no había restablecido el crecimiento sino al cabo de siete años, su tasa media se estableció en $+0.5 \%$ entre 1980 y 1988; esta vez la recuperación se produjo en un año: en 1995 la economía retrocedió 7\%, en 1996 avanzó 3\%. Entre 1995 y 2000 el ritmo anual se estableció alrededor de 5.5\% ${ }^{12}$ En marzo de 2000 la agencia de calificación Moody's otorgó a México el investment grade.

México se había convertido en un gran país exportador. Entre 1990 y 2000 México exporta tres veces más que Brasil. En 2009, México ocupa el lugar número 12 en el mundo por sus exportaciones, muy por delante de Brasil (el 27) y Argentina (el 37). Su comercio exterior (importaciones + exportaciones), que representaba $39 \%$ del PIB en 1991, rebasó el 60\% en 2005. Entre 1993 y 2012, la tasa media de crecimiento de las exportaciones mexicanas fue de $10.9 \% .{ }^{13}$ En veinte años el comercio con Estados Unidos se ha quintuplicado; pero esta cifra global disimula la profunda transformación que ha experimentado la economía mexicana: $82 \%$ de sus ventas exteriores son de productos manufacturados. El petróleo, que representaba aún en 2000 el 15\% del comercio exterior ha retrocedido. México tiene un perfil de país industrial.

En el cuadro de este nuevo modelo regionalizado, más de $50 \%$ de las exportaciones mexicanas corresponden a intercambios entre las empresas. El TLCAN, que ratifica la división regional del trabajo, constituye una forma de racionalización del sistema productivo estadounidense. Al unir la ventaja de la proximidad con la de un

12 De acuerdo con CEPAL, Balance preliminar de las economías de América Latina y el Caribe, 2000, Santiago de Chile.

${ }^{13}$ De acuerdo con K. P. Gallagher, R. Porzcanski, The Dragon in the Room: China and the Future of Latin American Industrialization, Redwood City, Stanford University Press, 2010, pp. 65-70; y Pierre Salama, Les économies émergentes latinoaméricaines, París, Armand Colin, pp. 58-59. Véase también Solange Monteiro, "Muito alem da mão de obra”, Conjuntura Econômica, vol. 68, núm. 8, agosto de 2014, p. 30. 
fuerte diferencial salarial, ${ }^{14}$ las deslocalizaciones industriales han aportado recuperación de competitividad a las empresas de Estados Unidos; en especial, gracias a una gran flexibilidad productiva donde la producción "justo a tiempo" (just in time) evita la gestión antieconómica de las existencias.

A su vez, los adversarios mexicanos del Tratado de Libre Comercio lamentaron una "maquiladorización" de México por la generalización de una economía de subcontratación que reposa en bajos salarios y en un débil proyecto nacional. Para estos críticos, el modelo de producción off shore norteamericano no es en absoluto industrializador; condenaría incluso a México al subdesarrollo. Es verdad que las maquiladoras, talleres de ensamblaje manual bajo control aduanero en la frontera norte, empleaban apenas un bajo $3 \%$ de componentes nacionales. Pero según otro enfoque la globalización tiene su propia lógica, que sólo puede beneficiar a México.

La propia dinámica de la manufactura de ensamblaje, el aprendizaje industrial que provee, la participación en las cadenas mundiales de valor y también, paradójicamente, el ejemplo del competidor chino, deberían librar gradualmente a México de la "trampa de los salarios bajos”. La modernización con gran intensidad de capital de nuevas unidades de producción impone una elevación del nivel de calificación, que México tiene los medios para enfrentar. Una primera generación de plantas de ensamblaje [screwdriver factories] puede ser un punto de partida para el progreso industrial, es decir, para una creciente complejidad técnica en la producción. De esta manera, se han visto aparecer recientemente "polos de competitividad de innovación” especializados en aeronáutica (Querétaro), informática (Jalisco) y biotecnología. El país es actualmente un gran productor de autopartes. Una cuarta parte de los vehículos importados en Estados Unidos vienen de México. La presencia de subcontratación del sector atrae las inversiones de ensamblaje

14 Los costos de producción no comprenden más que los salarios. Ahora bien, en México las tarifas de energía eléctrica son aproximadamente $80 \%$ mayores que aquellas de Estados Unidos, y las comunicaciones telefónicas internacionales cuestan el triple. Véase "Mexico's Reforms: The Power and the Glory", The Economist, 5 de julio de 2014. 
de las grandes marcas de fabricantes. ${ }^{15}$ Pero la modernización inducida por el TLCAN y el cambio de modelo económico no ha favorecido la diversificación geográfica del comercio exterior. Pese a una decena de acuerdos comerciales que cubren cerca de cincuenta Estados, México depende ante todo de la buena salud de la economía de su vecino del norte. Es así que más allá de la crisis de las hipotecas subprime de 2008-2009 la economía de México se hundió $-7 \%$, mientras que Brasil limitó su retroceso a $1 \%$.

El TLCAN ha sido un medio para adaptar la economía mexicana a las grandes corrientes de la globalización. En consecuencia, la apertura comercial, las desregulaciones y la "reforma del Estado", es decir la reducción de su perímetro, han liberado las fuerzas del mercado en todos los dominios, de implantaciones industriales a la ordenación del territorio. Una de las consecuencias indeseables ha sido el empeoramiento de los desequilibrios regionales y de la fractura norte-sur del país. Aunque hay quien ha creído que la "mano invisible" del mercado y de las fuerzas modernizadoras iba a allanar las diferencias y promover cierta homogeneización territorial, el tratado no ha permitido el reajuste de las zonas deprimidas. La brecha, por el contrario, se ha extendido entre los Estados del norte y del sur; las desigualdades de nivel de vida hacen preguntarse si sus habitantes pertenecen al mismo país. Se podría incluso suponer que las asimetrías del subcontinente norteamericano se han transferido al interior de México. Cuando el presidente Vicente Fox lanzó el plan de desarrollo regional Puebla-Panamá, que reunió a siete países del istmo centroamericano y a los siete estados federados más pobres del sureste mexicano, reconocía, en cierto modo, esta fractura abierta. En el plano social, el nuevo curso de la economía del que forma parte el tratado comercial de integración estuvo marcado al inicio por el crecimiento de la pobreza. Entre 1990 y 1996, el nivel de pobreza se duplicó. En 2000, 47\% de los mexicanos se encontraban por debajo de la línea de pobreza y $58.6 \%$ en las zonas rurales. ${ }^{16}$ Pero de 2000 a 2009 la lucha contra la

15 Entre las inversiones más recientes, se encuentran las de Nissan, Audi, Honda y Daimler.

${ }^{16}$ Fuente: CePal, Panorama social de América Latina, 2000 y 2009, Santiago de Chile. 
pobreza progresó notablemente en paralelo a la que se operó en los Estados sudamericanos, con la diferencia de que México no se benefició del boom de las materias primas. La pobreza retrocedió de 47 a $34.8 \%$. En cambio, las desigualdades sociales se atenuaron sólo ligeramente (el coeficiente de Gini pasó de 5.39 a 5.15) y aumentaron en 2011 con relación a $1985 .{ }^{17}$ Sin embargo, el fenómeno social más impactante, consecuencia directa de las reformas estructurales y de la apertura, fue la expansión del sector informal.

A este respecto, fue el ritmo de crecimiento del sector que sorprendió a México. Entre 1990 y 2008 la tasa de informalidad se duplicó, de 18.9 a $43.7 \%$. Estas cifras disimulan el desempleo y el subempleo, consecuencias previsibles del fin de la reforma agraria y del ejido, de las privatizaciones y la bancarrota de empresas provocadas por la competencia externa. La economía subterránea dio un salto hacia adelante. Las "microempresas" no registradas, el "autoempleo", los empleos precarios o no remunerados se multiplicaron. Así, cerca de $44 \%$ de los trabajadores mexicanos del siglo xxI no pertenecen al sector contractual y legalizado. Más aún, cuando les fue concedida una protección social mínima contributiva, ésta sólo fomentó el desarrollo de unidades económicas informales. ${ }^{18}$ Podemos preguntarnos sobre este aumento de la informalidad y aun cuestionarnos si no goza de un carácter funcional, a manera de la poca presión fiscal y de la emigración de los trabajadores por el modelo industrial adoptado por México.

\section{III) Cambio político y estatuto internacional}

Tres preguntas se imponen cuando se examina la dimensión política de las transformaciones que ocurrieron en México en los últimos dos decenios.

${ }^{17}$ Los ingresos del diez por ciento más rico eran en México treinta veces más altos que los del diez por ciento más pobre. Esta brecha es casi el doble de la de Estados Unidos (16.5\%) y el cuádruple de la que existe en Francia (7.4\%), según un documento de trabajo de la OCDE cuyas conclusiones se publicaron en El País (9 de diciembre de 2014) y en Le Monde (10 de diciembre de 2014).

18 Véase "The Reform that Got Away", The Economist, 31 de mayo de 2014. 
i) ¿Qué papel pudo jugar el "giro norteamericano" en la transición democrática y en la instauración de un régimen pluralista?

ii) ¿Afectó el tratado la autonomía externa del país y su diplomacia soberana?

iii) ¿Aumentó o se redujo la influencia internacional de México luego de su integración comercial con dos grandes potencias?

1) El "reconocimiento" de Washington de los gobiernos mexicanos fue siempre decisivo para su legitimidad, especialmente durante la tormenta revolucionaria. Sin embargo, Estados Unidos, si bien no se hacía ilusiones sobre el carácter autocrático del régimen posrevolucionario, no exigía más que el respeto de sus intereses y la estabilidad política. Asimismo, un sistema autoritario electivo capaz de renovar regularmente a sus dirigentes convenía a la perfección a los estadounidenses. Los gobiernos sucesivos de Estados Unidos siempre prefirieron una democracia ficticia a un régimen competitivo imprevisible e inestable. En consecuencia, saludaron complacidos el largo proceso de liberalización electoral lanzado en la década de 1970 que se contentaba con abrir gradualmente a la oposición un espacio de representación parlamentaria sin por ello cederle nada de poder real.

Es así que a pesar de las dudas en torno a la victoria del PRI en las elecciones presidenciales de 1988, las nuevas autoridades obtuvieron el pleno apoyo de Estados Unidos. La naturaleza del régimen, las modalidades de la elección del presidente "reformador" se olvidaron pronto, aunque la liberalización de la economía no se acompañase de una apertura concomitante. Estaba claro para la administración estadounidense que un poder fuerte y no compartido era indispensable para llevar a buen término los cambios comprometidos e incluso establecer relaciones más estrechas y confiables con Estados Unidos. ${ }^{19}$ Puede suponerse que la gran mayoría de las reformas socialmente costosas e impopulares habrían sido más difíciles, si no imposibles, en una democracia transparente

${ }^{19}$ Cf. el artículo de Paul Krugman citado, así como el contenido de un comunicado del embajador estadounidense John Negroponte publicado por la prensa mexicana, Proceso, 11 de mayo de 1991. 
y competitiva. Sin adelantar la hipótesis de que la perspectiva del TLCAN prolongó la existencia de la autocracia revolucionaria, es probable que la apuesta norteamericana de México no tuvo apenas incidencia en la instauración de un régimen pluralista competitivo. De hecho, la alternancia fue otorgada por el régimen, a su ritmo y sin tomar riesgos, en el marco de instituciones creadas para y por el partido revolucionario hegemónico.

2) La política exterior del México posrevolucionario, esencialmente defensiva, reposa en un cuerpo de principios jurídicos intangibles que conforman una "diplomacia de derecho". Estos principios son, entre otros: la defensa absoluta de la soberanía nacional, la condena de las intervenciones extranjeras (incluso las multilaterales y colectivas) en un Estado soberano, la solución pacífica y negociada de los conflictos internacionales. Fue así como México adoptó la doctrina Calvo, que impone el trato nacional de las empresas extranjeras, les prohíbe llamar a su gobierno en caso de litigio y los obliga a recurrir para este efecto a los tribunales locales. Esta doctrina latinoamericana de inicios del siglo xx se transcribió en la Constitución mexicana (artículo, 27, I). Además, esta diplomacia defensiva pone generalmente a México del lado de los Estados débiles y vulnerables. Es para muchos parte del prestigio internacional del país desde la década de 1930.

Puede estimarse que un tratado comercial no puede cuestionar ni la tradición diplomática ni el arsenal jurídico de Tlatelolco; y sin embargo... Así, ciertas cláusulas del tratado pudieron provocar evoluciones en el comportamiento de México hacia el exterior. El tratado prevé por ejemplo formalidades de arbitraje comunes a los tres países en caso de discrepancias, y que son incompatibles con la doctrina Drago. ${ }^{20}$ Se dirá detalle técnico, pero constituía un primer contratiempo para los dogmas sacrosantos inscritos en la ley fundamental. Una interdependencia aceptada, léase deseada, no podía suceder sin distensión ni sin algunas evoluciones.

${ }^{20}$ En ausencia de corte permanente, el arbitraje se confía a "comisiones ad hoc" o, para inversiones, al CIRDI (International Center for Settlement of Investment Dispute), que depende del Banco Mundial. 
Así, en 1996 una reforma constitucional (artículo 30) autorizó la doble nacionalidad: la adopción de otra nacionalidad no acarreaba ya la pérdida de la ciudadanía mexicana. Luego de la alternancia de 2000, México pareció cambiar su posición sobre algunos temas internacionales sensibles, como las relaciones con Cuba. Mantener relaciones normales con Cuba era desde 1961 la piedra de toque y el símbolo de la independencia de México frente a Estados Unidos. Un voto alineado con Washington en el Consejo de los Derechos Humanos de las Naciones Unidas sobre la situación cubana, ${ }^{21}$ que no tenía el apoyo ni del Congreso ni de la opinión pública, se interpretó como una inflexión de la política exterior de México, o sea como punto de partida de una "nueva diplomacia" acorde con la "nueva economía" del país. No obstante, México no se alejó de sus principios por mucho tiempo. Como miembro no permanente del Consejo de Seguridad de las Naciones Unidas, no avaló la invasión militar a Iraq en 2003. Su actitud pudo fluctuar para evitar un enfrentamiento con Estados Unidos, pero, a pesar de fuertes presiones, no se doblegó ante Washington y mostró una voluntad de independencia que no se esperaba más. La tradición defensiva y jurídica de la diplomacia mexicana se relajó acaso y se volvió menos intransigente a consecuencia del giro hacia el Norte, pero no se abandonó.

3) En lo que se refiere al rol de México y a su influencia internacional posterior al TLCAN, surge una constatación inicial. La acción exterior de México, especialmente en 2000 y 2012, pareció concentrarse sobre un solo socio, Estados Unidos, y se limitó a una sola carpeta, a un solo asunto: para Vicente Fox, la migración; para Felipe Calderón, la "guerra contra el narcotráfico". Más en general, durante el periodo transitorio de apertura comercial gradual, México concentró sus esfuerzos en el "diálogo exlusivo" con Esta-

${ }^{21}$ En el Consejo de Derechos Humanos, México votó a favor de la designación de un relator especial y de inspecciones en el lugar para examinar la situación de los derechos humanos y las libertades en Cuba. Véase Raúl Bernal Meza, "México, treinta años de política exterior", Carta Internacional (São Paulo), vol. 2, núm. 1, 2007, p. 45; y Andrés Rozental, "Fox’s Foreign Policy Agenda: Global and Regional Priorities", en Luis Rubio, Susan Kaufman Purcell (coords.), Mexico under Fox, Boulder, Lynne Rienner, 2004, pp. 87-110. 
dos Unidos. Esto sucedió pese a los intentos anunciados de diversificación comercial y de los gestos retóricos con relación al resto del continente. Estas políticas unipolares se topan a veces con la defensa intransigente de la soberanía nacional. Dos ejemplos, entre otros, lo demuestran.

$\mathrm{Al}$ comienzo de su sexenio, el presidente Fox creía que era posible profundizar la integración regional mexicana más allá del comercio. Deseaba ante todo que la libre circulación de personas complementara la de los productos y los capitales. También tenía grandes esperanzas sobre una ayuda tripartita a las zonas deprimidas gracias a la formación de fondos estructurales a la manera europea, destinados a superar los desequilibrios regionales. Los atentados del 11 de septiembre pusieron fin al sueño integracionista mexicano y a la ilusoria Comunidad Norteamericana. Estados Unidos se cerró sobre sí mismo. La "seguridad de la patria" (Homeland Security) se volvió la prioridad para Washington. La "guerra contra el terrorismo" fue en adelante el gran proyecto de la presidencia de George W. Bush. El imperio, olvidado de sus vecinos, contraatacó en Medio Oriente. El "realismo geográfico" mexicano fue la víctima colateral de Al-Qaeda.

Con todo, la "fortaleza América", a pesar de (o a causa de) su reacción securitaria, no interrumpió el diálogo con México y Canadá, aunque su preocupación principal se encontraba en Afganistán e Iraq. Se realizaron periódicamente reuniones trilaterales y cumbres. Estados Unidos propuso así en marzo de 2005 a sus dos socios en el tratado la creación de un "espacio de seguridad norteamericano" y de una Alianza para la Seguridad y la Prosperidad en América del Norte (ASPAN). México aceptó este proyecto como una suerte de sustituto para la profundización que deseaba de la integración regional; en realidad, el objetivo de Washington era extender la Homeland Security a los dos países vecinos. La frontera de seguridad de Estados Unidos al sur se transfirió del Río Bravo al Río Suchiate, en la frontera con Guatemala. Este proyecto fue criticado en los tres Estados miembros como una "militarización del TLCAN". ${ }^{22}$ Por lo que respecta a México, el dispositivo de la ASPAN 
parecía estar además en las antípodas de la política de rechazo permanente de toda cooperación militar con Estados Unidos, que había prevalecido desde los años cincuenta. Contradecía, por decir lo menos, la decisión reciente de México de retirarse del Tratado Interamericano de Asistencia Recíproca (TIAR) de 1947, considerado un vestigio de la Guerra Fría. Acaso, además, las autoridades mexicanas estimaban que este desarrollo político militar del TLCAN demasiado marginal para Estados Unidos, sería discreta y firmemente enterrado por Canadá. Eso es lo que ocurrió: la ASPAN nunca se formalizó ni superó la etapa de los intercambios regulares entre los dirigentes de los tres países.

Años más tarde, bajo otra presidencia, México solicitó el apoyo militar estadounidense para llevar a buen término la "guerra contra el narcotráfico", gesto sin precedente en la historia posrevolucionaria. De esto derivó la Iniciativa Mérida, firmada por los dos presidentes en marzo de $2007,{ }^{23}$ la cual preveía el suministro a México de equipos de seguridad. Los suministros estadounidenses, con todo, estuvieron limitados, si se los compara con la ayuda otorgada efectivamente en circunstancias similares en el marco del Plan Colombia. Quizás porque México, a diferencia de Colombia, no había aceptado la presencia de instructores militares extranjeros.

Asimismo, no sorprende que México, a causa de este encuentro exclusivo y prolongado con Estados Unidos, haya perdido, a pesar de su potencial y su historia, un poco de su estatura de líder continental. Su área de influencia parece incluso haberse reducido. Mientras que en las décadas de 1970 y 1980 el país gozaba de un destacado prestigio internacional, ${ }^{24}$ en el siglo Xxi su proyección

http:/ / www.projectcensored.org:top-stories/articles/é-security-and-prosperitypartnership-militarized-nafta

${ }^{23}$ Véase "Sólo con el apoyo de Estados Unidos podemos afrontar al Narco", entrevista a Patricia Espinosa, secretaria de Relaciones Exteriores de México, El País, 12 de mayo de 2009.

${ }^{24}$ Esto lo atestigua, entre otras cosas, la creación del Sistema Económico Latinoamericano (SELA) en los años setenta, la Conferencia Norte Sur de Cancún sobre la Cooperación y el Desarrollo (1981) y el papel de México en el proceso de paz en América Central (1983-1992). 
exterior manifiesta una ambición relativamente modesta. Por quedarse en el mero dominio latinoamericano, la comparación con Brasil es esclarecedora. La gran nación emergente de América del Sur ha suscitado a partir de 2000 un reagrupamiento regional, del cual es el animador y el beneficiario. La Comunidad de Naciones Sudamericanas, mudada en Unión de Naciones Suramericanas (Unasur) en 2008, es un proyecto de organización regional en círculos concéntricos de los cuales Brasil sería el centro. Paralelamente, de alguna forma, cuando México lanzó su plan de desarrollo PueblaPanamá, puede decirse que la esfera de influencia de este gran actor regional se estrechó. ¿Sería el TLCAN la causa de esta contracción?

Es verdad que América del Sur no tiene importancia crucial para México, especialmente en materia económica. Sin embargo, en la Cumbre de las Américas de Mar del Plata en 2005, en la que Brasil y Argentina entorpecieron el proyecto panamericano del Área de Libre Comercio de las Américas (AlcA), México se presentó como su principal defensor. Se trataba en cierta forma de extender el TLCAN al conjunto del continente, lo que habría permitido a México escapar del perímetro norteamericano y regresar con fuerza al concierto de naciones latinas. Pero el fracaso del Alca regresó a México a la monogamia y a un relativo aislamiento. Esta soledad podría percibirse por ejemplo en sus tareas en las organizaciones internacionales. En la Organización de Estados Americanos en 2005 y en el Fondo Monetario Internacional en 2011, los candidatos de México para altos cargos, pese a su capacidad y experiencia, no recibieron el apoyo de la mayoría de los Estados latinoamericanos, ${ }^{25}$ como si se sospechara que las personalidades mexicanas, apoyadas (discretamente) por Estados Unidos, serían demasiado sensibles a sus presiones. La imagen dominante de México es pues la de un país dependiente de la economía norteamericana, un aliado privilegiado de Washington.

${ }^{25}$ En el caso de la oEA, se trataba de Ernesto Derbez, dos veces secretario (de Economía y de Relaciones Exteriores), y en el del FMI, del economista Agustín Carstens, actual gobernador del Banco de México. 
México, sin embargo, hizo grandes esfuerzos diplomáticos para reintegrarse a América Latina, a la cual pertenece. La reconciliación con Cuba, gradual y compleja ha sido un primer paso, simbólico mas decisivo. En adelante, México jugará un rol crucial e interesado en la creación de una nueva organización política del continente, la CELAC, Comunidad de Estados Latinoamericanos y Caribeños, que nació del acercamiento del Grupo de Río y de la Caricom. Lanzada en Brasil (Bahía, 2008) y en México (Cancún, 2010), la cELAC, formalmente fundada en Venezuela en 2011, incluyó a Cuba y respondió a los intereses permanentes de México. En efecto, su esfera de influencia abarca el "Mediterráneo americano" y al mismo tiempo le rinde beneficios por su dualidad política. El México contemporáneo se percibe siempre como un puente, es decir como intermediario indispensable entre las dos Américas. La CELAC puso pues fin a un aislamiento que la debilitaba, incluso ante sus socios de América del Norte.

Además, su proximidad asumida con Estados Unidos y su situación bi-oceánica le han permitido participar en nuevos reagrupamientos regionales y en iniciativas de integración innovadoras. México fue, en efecto, uno de los Estados fundadores de la Alianza del Pacífico en junio de 2012, la cual reúne a los grandes países del litoral oriental [sic] de América del Sur: Colombia, Perú, Chile. Estos países tienen con México varios rasgos en común. Han firmado acuerdos de libre comercio con Estados Unidos, que constituyen el principal destino de sus exportaciones. Tienen también relaciones comerciales importantes con los países asiáticos. México, Perú, Chile pertenecen de hecho con Estados Unidos y China al Foro de Cooperación Económica Asia-Pacífico (APEC), cuyo objetivo es "facilitar las inversiones y el comercio" entre los países miembros. Es momento de acuerdos comerciales planetarios. El presidente Barack Obama aspira a dotar con un instrumento al "pivote asiático" de su estrategia global: el Acuerdo Estratégico Trans-Pacífico de Asociación Económica (тPP), del cual China queda ausente. Este acuerdo, si ve la luz, ${ }^{26}$ abarcaría un tercio del

${ }^{26}$ Además de los obstáculos bilaterales, parece difícil que el Congreso estadounidense de mayoría republicana otorgue al presidente actual los medios legislativos (Trade Promotion Authority) para llevar esta iniciativa a su término. 
comercio mundial entre doce Estados que representan $40 \%$ del PIB global. Entre los doce Estados figuran tres países de América Latina, entre ellos México, al lado de Chile y de Perú. Incluso si no se puede prever el resultado de esta iniciativa, puede afirmarse que México ya no está aislado.

En la Cumbre de Toluca en febrero de 2014, donde se celebraron los veinte años del TLCAN, los dirigentes de los tres Estados no han cesado de mirar de reojo a Asia, en vista de reactivar la zona de libre comercio norteamericana y de superar ciertas limitaciones. Es posible, como lo declaró el canciller de México, que el TLCAN esté en vías de crear "la región más competitiva del mundo". ${ }^{27}$ Queda por verse si eso bastará para asegurar la prosperidad de México y de los mexicanos.

\section{Traducción de Gabriel Ramos}

\section{Bibliografía}

Aguilar Camín, Héctor, "Notas sobre nacionalismo e identidad nacional. La invención de México”, Nexos, 1 de julio de 1993.

Bernal Meza, Raúl, "México, treinta años de política exterior", Carta Internacional (São Paulo), vol. 2, núm. 1, 2007, pp. 32-51.

Bizberg, Ilan, "Le Mexique et l'AlenA, inégalité et démocratie”, en Martine Azuelos, María Eugenia Cosío-Zavala (coord.), Intégration dans les Amériques. Dix ans d'AlENA, París, Presses de la Sorbonne Nouvelle, 2005.

Calderón, Chelius, Leticia y Jesús Martínez Saldaña, La dimensión política de la migración mexicana, México, Instituto Luis Mora, 2004.

Cárdenas, Cuauhtémoc, “TLC, una propuesta alternativa”, Nexos, junio de 1991.

CEPAlc, Une décennie de développement social en Amérique latine, 1990-1999, Santiago de Chile, Cepalc-Iheal, 2004.

Conchello, José Ángel, véase por ejemplo, $E l$ TLC, un callejón sin salida, México, Grijalbo,1992.

${ }^{27}$ Declaración de José Antonio Meade, Le Monde, 18 de febrero de 2014. 
Dauzier, Martine (coord.), Le Mexique face aux Etats Unis: stratégie et changements dans le cadre de l'ALENA, París, L'Harmmattan, 2004.

Davidson, Jeffrey, United States and Mexico: The Bear and the Porcupine, Nueva York, Marcus Wiener, 2004.

Deblock, Christian, "Nafta: Springboard or Trap”, en Claude Auriol y Aline Helg (coords.), Latin America, 1810-2010: Dreams and Legacies, Londres, Imperial College Press, 2012.

Krugman, Paul, "The Uncomfortable Truth about NAFTa: It's Foreign Policy, Stupid”, Foreign Affairs, 5, 1993, pp.13-19.

Gallagher, K. P., R. Porzcanski, The Dragon in the Room: China and the Future of Latin American Industrialization, Redwood City, Stanford University Press, 2010, pp. 65-70.

Meyer, Jean, Enrique Krauze y Cayetano Reyes, Historia de la Revolución Mexicana (1921-1928). Estado y sociedad con Calles, México, El Colegio de México, 1977.

Meyer, Jean, La Révolution mexicaine, París, Calmann Lévy, 1972.

Monteiro, Solange, "Muito alem da mão de obra", Conjuntura Econômica, vol. 68, núm. 8, agosto de 2014.

oEcD, Economic Surveys, Mexico, París, noviembre de 2005.

Ojeda, Mario, Alcances y límites de la política exterior de México, México, El Colegio de México,1978.

Oppenheimer, Andrés, Bordering on chaos, Guerillas, Stockbrokers, Politicians and Mexico's Road to Prosperity, Boston, Little Brown,1997.

Pastor, Robert y Jorge Castañeda, Limits of Friendship: The Unites States and Mexico, Nueva York, A. Knopf, 1988.

Pellicer de Brody, Olga (coord.), La política exterior de México, desafíos en los ochenta, México, CIDE, 1983.

_- "Las relaciones exteriores: interdependencia con Estados Unidos o Proyecto nacional", en Pablo González Casanova y Enrique Florescano (eds.), México hoy, México, Siglo XXI, 1984.

PNUD-OEA, Nuestra democracia, México, FCE, 2010.

Riding, Alan, Distant Neighbors: A Portrait of the Mexicans, Nueva York, A. Knopf, 1984.

Roett, Riordan, Political and Economic Liberalization in Mexico at a Critical Juncture, Boulder, Lynne Rienner, 1993.

Rouquié, Alain, Le Mexique, un État nord-Américain, París, Fayard, 2013. 
Rousseau, Isabelle, Modernidad con pies de barro, 1988-1994, México, CEMcA, 1995.

Rozental, Andrés, "Fox’s Foreign Policy Agenda: Global and Regional Priorities", en Luis Rubio, Susan Kaufman Purcell (coords.), Mexico under Fox, Boulder, Lynne Rienner, 2004, pp. 87-110.

Salama, Pierre, Les économies émergentes latinoaméricaines, París, Armand Colin, 2012.

Salinas de Gortari, Carlos, México, un paso difícil a la modernidad, Barcelona, Plaza y Janés, 2000.

Vagnoux, Isabelle, Les Etats Unis et le Mexique. Histoire d'une relation tumultueuse, París, L'Harmattan, 2003.

Vega Cánovas, Gustavo, México ante el libre comercio con América del Norte, México, El Colegio de México, 1991.

Zedillo Ponce de León, Ernesto, "NAFTA, 20: Where We Go From Here”, Americas Quarterly, 20 de febrero de 2014, en http://www.americasquarterly.org.content/nafta-20-where-we-go- here 